\title{
Making of the Asian Seismological Commission (ASC): A Chinese Perspective
}

\author{
Zhu Chaunzhen ${ }^{1, *}, \mathrm{Wu}$ Zhongliang ${ }^{2}$ and $\mathrm{Li} \mathrm{Li}^{1}$ \\ ${ }^{1}$ Institute of Geophysics, China Earthquake Administration, 100081 Beijing, China \\ ${ }^{2}$ Institute of Earthquake Forecasting, China Earthquake Administration, 100036 Beijing, China \\ *E-mail: zhucz304@icloud.com
}

\begin{abstract}
This article is dedicated to the Silver Jubilee Year of Asian Seismological Commission (ASC) and provides details of its evolution from its nascent stage from a Chinese perspective. The review includes the seeding of the idea of ASC, its formation, the General Assemblies and the International Conference on Continental Earthquakes (ICCE) series in which ASC played an active role. The paper also highlights the profiles of the Commission as well as its role in the development of Asian seismology.
\end{abstract}

\section{PREPARATION FOR AN ASIAN SEISMOLOGICAL COMMISSION (ASC)}

In 1988, UNESCO sponsored an "International Symposium on Earthquake Prediction" in Lisbon, where Prof. Zhu Chuanzhen, known for the first successful earthquake prediction in China was invited. It was after the March 8, 1966 Xingtai earthquake of M6.8, Zhou Enlai, the Premier of the Peoples' Republic of China immediately asked the Chinese scientists to launch earthquake prediction studies in the Xingtai region of the Hebei Province. The Chinese seismologists started monitoring earthquake precursors in the vicinity of the affected area to see patterns and trends in the data. Prof. Zhu who was analyzing precursor data in the field observed certain anomalies, which he thought was positive signs of an impending major earthquake and contacted his headquarters and made the prediction. A strong aftershock occurred after his prediction and probably this was the first successful earthquake prediction in China.

In the Lisbon symposium Prof. Zhu Chuanzhen made a presentation on earthquake prediction studies in China that attracted wide attention of the international scientific community. This encouraged him to work with international seismologists to exchange ideas on this topic to develop Chinese seismology. A decade after the first successful prediction there were some significant successes and failures in earthquake prediction experiences till 1976 in China. While the most successful was the prediction and pre-earthquake evacuation of the February 4, 1975, $M_{S} 7.3$ Haicheng earthquake, the July $28,1976, M_{S} 7.8$ Tangshan earthquake was not predicted in the very next year. This partial success and failure underlined the significance of international and regional cooperation on problems of earthquake prediction, hazard evaluation and preparedness, mitigation, and management of earthquake disasters.

In 1992, Prof. Zhu Chuanzhen and Dr. Zhang Xiankang, a seismologist working on deep Earth exploration attended the 23rd Assembly of the European Seismological Commission (ESC) in Prague and were impressed to see the contributions of ESC in European and global seismology. ESC that was established as the first Regional Commission of the International Association of Seismology and Physics of the Earth's Interior (IASPEI) in 1951 gave an idea to establish a similar commission for the Asian region. Prof. Zhu discussed the issue with his colleague Dr. Zhang and with Secretaries General Dr. Mayer Rosa and Dr. Peter Suhadolc who responded positively to the idea.

Initially it was decided that both the Seismological Society of China (SSC) and the Seismological Society of Japan (SSJ) would jointly put forward the proposal for ASC, but for some reasons it could not materialize. In 1993 SSC unilaterally drafted a proposal and sought comments from other countries and got a very positive response including from the SSJ. In the latter half of 1993, Prof. Zhu along with Chen Yun-tai who was the President of SSC and Dr. Chen Zhangli, Deputy Director-General of the State Seismological Bureau, SSB, now China Earthquake Administration, CEA, attended a seminar on East Asia seismological studies in Tokyo in which they held a meeting explaining the proposal of an ASC under the aegis of IASPEI. Delegates from 15 countries that included India, Iran, Japan, Korea, Malaysia, The Philippines, and Thailand were present in the meeting and unanimously endorsed the idea by appointing an ad hoc Working Group under Prof. Zhu to proceed on the matter.

The State Seismological Bureau (SSB) and the Chinese National Committee for IASPEI also endorsed the proposal in China. Prof. Zhu made a presentation on the proposal before the IASPEI Executive Committee (EC) meeting in 1994, which was chaired by the then President of IASPEI Prof. A. Nikolaev. The EC agreed to the formation of the Asian Seismological Commission (ASC) as one of its Regional Commissions under the umbrella of the IASPEI and suggested to include countries in Oceania region also.

\section{ESTABLISHMENT OF THE ASIAN SEISMOLOGICAL COMMISSION (ASC)}

A preparatory meeting of the ASC was held in Guangzhou in 1995 where delegates from China, India, Iran, Japan, Korea, Philippines and Vietnam participated. Dr. Eric Robert Engdahl, the Secretary General of IASPEI, was present and announced the support of IASPEI to ASC both academically and financially.

Taking advantage of the first opportunity during the IASPEI Regional Assembly in 1996 from August 1-3 to commemorate two decades of the July 28, 1976, Tangshan earthquake the formation of ASC was officially announced. More than 380 delegates attended the IASPEI Regional Assembly that included Prof. C. Froidevaux, President of IASPEI, Dr. P. Suhadolc, Secretary General of ESC, and Chen Zhangli, Director-General of SSB.

Dr. Engdahl chaired the first Business Meeting of ASC where participants from 19 countries, Australia, Azerbaijan, Bangladesh, China, India, Iran, Israel, Japan, Kazakhstan, Korea, Kyrgyzstan, Nepal, New Zealand, Pakistan, Russia, Thailand, Philippines, Turkey and Vietnam were present. In the meeting the Charter and By-laws of ASC were passed and the first ASC Bureau was elected. Prof. Harsh Gupta (India) as President, Zhu Chaunzhen (China) as Secretary General with Profs. H. Hamada (Japan) and G. Gibson (Australia) as 


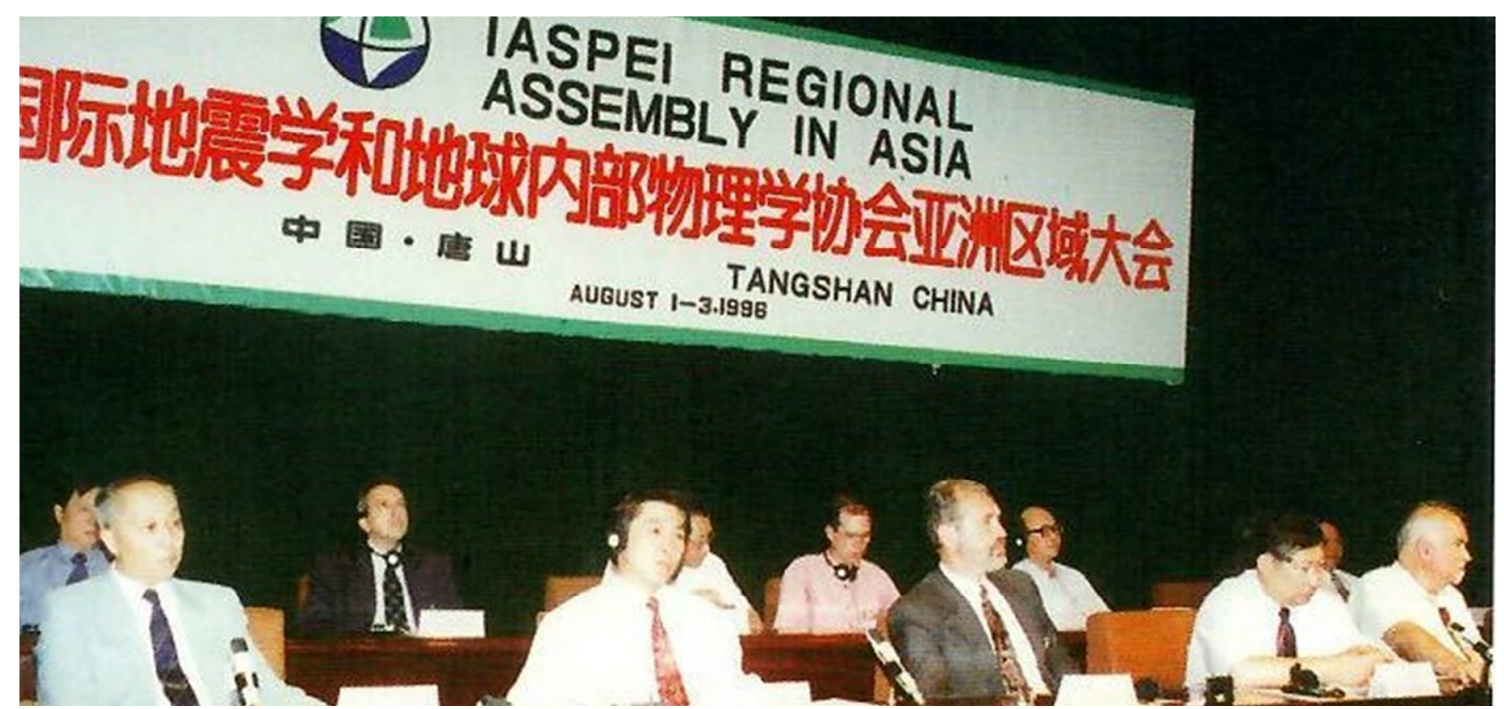

Fig.1. IASPEI Regional Assembly in Asia. (Reproduced from China Earthquake Yearbook 1996, Seismological Press 1998, in Chinese)

vice presidents were the founding Bureau members. The ASC secretariat was hosted at the Institute of Geophysics of SSB. Prof. Harsh Gupta designed the ASC logo and was approved by the Bureau.



Fig. 2. Logo of ASC, designed by Harsh Gupta

Asia, with her vast territory and large population, has the most intense seismicity and earthquake disasters in the world. Considering that most countries in Asia and southern Pacific region are developing, with limited economic resources and research activities, it is desirable to bring together their expertise and experience in seismology and related disciplines to mitigate earthquake disasters.

The objectives of ASC are to promote scientific cooperation and exchange among its national members, to upgrade research activities, to strengthen disaster mitigation and to cooperate with other international and regional organizations.

The recent quarter century has proved that ASC has done a great job. ASC, together with ESC, played an important role in the works of IASPEI. Since 2001 ASC has been taking over the missions of the IASPEI commission for developing countries. ASC had cooperation with other IASPEI commissions, such as the Commission on Seismic Hazard, Risk and Strong Ground Motion (SHR).

\section{TRACING ASC GENERAL ASSEMBLIES OF 25 YEARS}

The 25 years of the completion of ASC with 12 Biennial General Assemblies is a sign of great success in which ESC and IASPEI played major roles. Emulating the success of ASC, two other Regional Commissions of the IASPEI viz., the Latin American and Caribbean Seismological Commission (LCSC) and the African Seismological Commission (AfSC) were established in 2013 and 2014, respectively.

The letter of congratulation on the establishment of ASC in 1996 by Dr. Eric Robert Engdahl and the speech at ASC party in 2004 by Dr. Peter Suhadolc needs special mention. Both of them echoed the same sentiments when they said "Long Live Asian Seismological Commission".

The IASPEI Regional Assembly in Tangshan in 1996, in which establishment of the ASC was officially announced was considered as the $1^{\text {st }}$ General Assembly of ASC. The $2^{\text {nd }}$ General Assembly was held in Hyderabad, India from December 1 to 3, 1998, with about 200 participants with 189 abstracts. Before the Assembly a two-week international training course on seismological observation, data analysis and exchange was organized. Experts from GFZ, Germany led by Peter Bormann played an active role in the training course. For many of the young scientists from China, it was the first time to participate in international exchange abroad, Zhou Shiyong, now a Professor at the Peking University with several international publications is one among them.

The $3^{\text {rd }}$ General Assembly was held in Tehran, Iran, from October 10 to 12,2000 . 270 abstracts were submitted and 160 participants from 23 countries attended the Assembly. A Pre-Assembly training course was organized, emphasizing seismic hazard assessment and earthquake prediction study. Students of the 1998 training course, Prof. Wu Zhongliang being one of them became lecturers in this training. Dr. S. Yu. Blassanian (Armenia) was elected as the President with Dr. D. Rhoades (New Zealand) and Prof. M. Gheitanchi (Iran) as vice Presidents in the new Bureau. Prof. Zhu Chuanzhen continued as the Secretary General.

In a very interesting study presented in the Assembly, Su et al. (2000) reported that the "impact factor of the earthquakes" that is, the scientific output in terms of number of papers published after each damaging earthquake in Asia with the exception of Japan was very much lower than that of Europe and America. Today, after twenty years the situation has changed, probably the formation of ASC has greatly helped. In 2018, statistics showed that earthquakes in Asian countries had much better scientific outputs with 2011 Tohoku Japan earthquake taking the first position and 2008 Wenchuan earthquake in China being the second in the world.

The $4^{\text {th }}$ General Assembly was held during 24-26, 2002 in Kathmandu, Nepal. This assembly was to some extent marred by the murder in the royal family of Nepal, and the conflict between governmental and anti-governmental forces. Nevertheless, some 200 experts from 22 countries attended the meeting, with about 110 


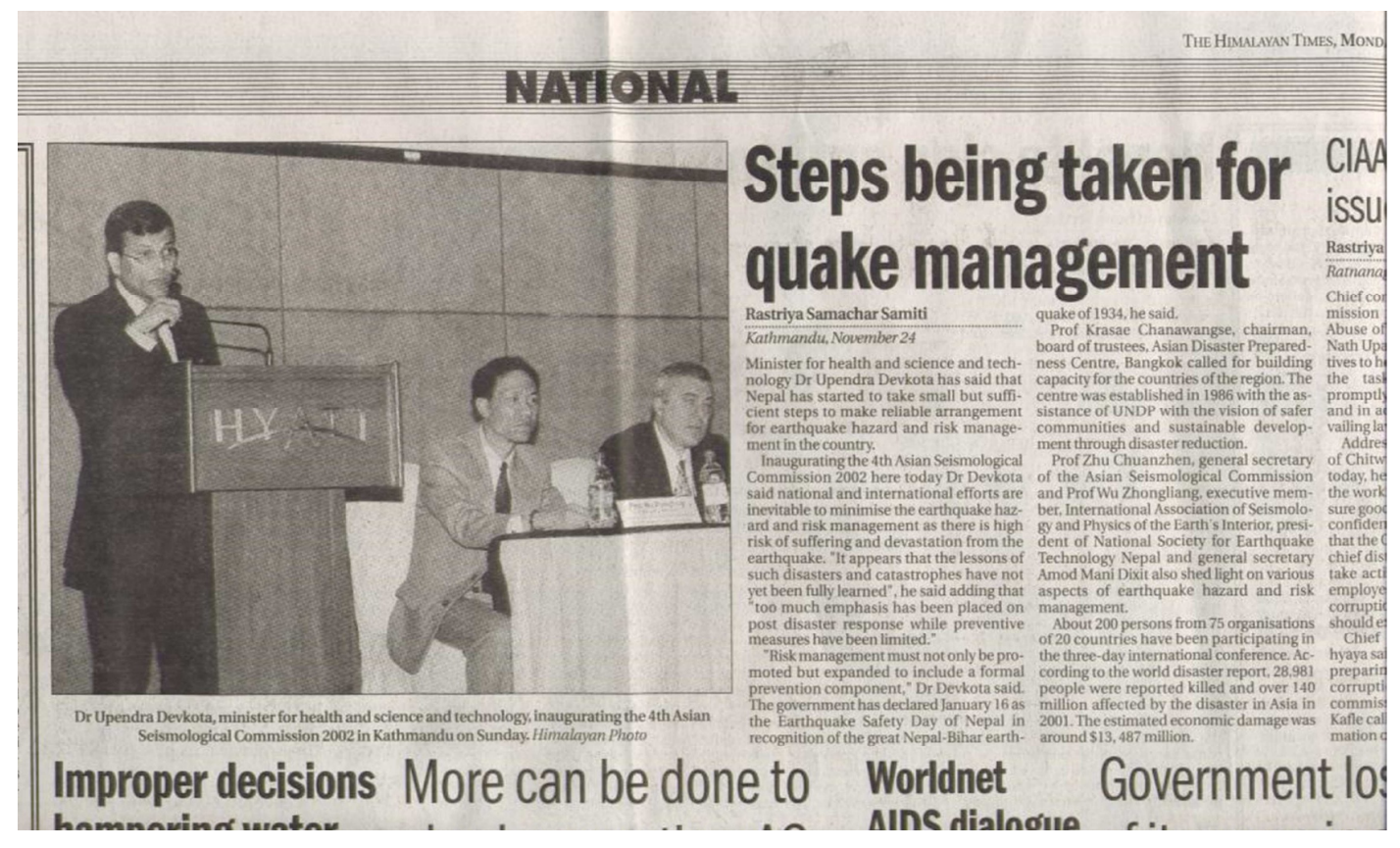

Fig.3 Media coverage reporting the ASC Assembly in Kathmandu, 2002

abstracts submitted. The media in Nepal gave a wide coverage of the Assembly highlighting the importance of earthquake hazard in Asia, especially in the Himalaya.

Before the meeting, ASC and Asian Disaster Preparedness Center (ADPC) jointly organized the international training course on the reduction of urban seismic vulnerability. After the meeting, the full-paper proceedings of the Assembly were collected and circulated (Dixit, 2004).

From October 18 to 21,2004 , the $5^{\text {th }}$ General Assembly of ASC was held in Yerevan, Armenia. Some 275 participants from 51 countries made a record of wide participation of the ASC assemblies. A PreAssembly training course with stress on seismic data analysis and seismic hazard assessment was organized. During the meeting, the Premier of Armenia met the delegates of the Assembly. Slogans of ASC were displayed along the main street of the capital. The Assembly elected the new Bureau, with Zhu Chuanzhen (China) as President, S. Goldin (Russia) and Cao Dinh Trien (Vietnam) as Vice Presidents, and K. Hirahara (Japan) as Bureau member. Dr. R. K. Chadha (India) was elected as the second Secretary General of the ASC since its inception. The ASC secretariat was thus moved to the National Geophysical Research Institute (NGRI) in Hyderabad, India, the

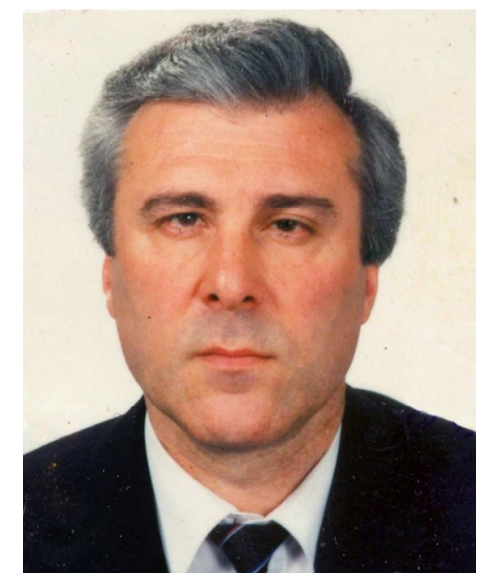

Fig.4. Prof. S. Yu Balassanian (1948-2004), president of ASC (20002004) place of work of Dr. Chadha.

It was tragic that shortly after the meeting, Prof. Balassanian passed away in a traffic accident on November 23, 2004 at the prime age of 57.

On December 26, 2004 Mw9.3 Sumatra earthquake generated the Indian Ocean Tsunami that claimed more than 300,000 human lives. In response to this disaster, ASC co-sponsored several activities on the study of earthquake-generated tsunamis and reduction of disaster risks of earthquakes and tsunamis. From November 7 to 9 , the $6^{\text {th }}$ General Assembly of ASC was held in Bangkok, Thailand. The unexpected coup in Thailand made the organization of the Assembly difficult but with the efforts of the ASC leaders and local organizing committee, the Assembly was conducted smoothly. The meeting arranged 5 sessions, namely (1) Subduction zone, seismology and tsunami; (2) Strong motion seismology; (3) Earthquake forecasts; (4) Management/reduction of seismic risk; and (5) Observational seismology, together with a special session on the Kashmir earthquake on October 8 at the Pakistan-Indian border. ASC and ADPC organized a Pre-Assembly training course.

The $7^{\text {th }}$ General Assembly was held from November 24 to 28, 2008, in Tsukuba, Japan along with the Fall Meeting of the Seismological Society of Japan (SSJ). The theme of the meeting was 'Sharing of Up-to-date Science and Technology to Reduce Earthquake Disaster in Asia'. Nearly 800 participants from 39 countries marked another peak of participation in the ASC Assemblies. Disaster Prevention Research Institute (DPRI) at Kyoto University organized a PreAssembly training course on seismology during November 18-21. The Assembly organized a special session on the Wenchuan earthquake of May 12, 2008. Prof. Zhu Chuanzhen was interviewed by news media and given a wide coverage. A new ASC Bureau was elected with Prof. Kazuro Hirahara (Japan) as President with Dr. Cao Dinh Trieu (Vietnam) and Prachaub Sumallee (Thailand) as Vice Presidents, Ding Zhifeng (China) as a Bureau member, and Dr. R. K. Chadha was re-elected as the Secretary General. In the Assembly, ASC conferred an Award to Prof. Zhu Chuanzhen for his Outstanding Service to ASC. Dr. Yuzo Ishikawa and Kunihiko Shimazaki were conferred an Award by the Founder President for Service to ASC. This is the first time for ASC to confer awards.

From November 8 to 10,2010 , the $8^{\text {th }}$ General Assembly was held 
in Hanoi, Vietnam. A Pre-Assembly training course focused on the reduction of seismic disasters was also organized.

In 2011 after the March 2011 Tohoku Japan great M9.0 earthquake, the East Asia Seminar on Earthquake Studies was held in Beijing, jointly organized by China Earthquake Administration (CEA), Japan Meteorological Agency (JMA), and Korean Meteorological Agency (KMA). ASC, together with other international organizations, contributed to the organization of the Seminar and the passing of the Beijing Understanding.

The $9^{\text {th }}$ General Assembly was held in Ulaanbaatar, Mongolia during September 17-20, 2012. 200 scientists attended the meeting. The Chinese sent a big delegation of 30 scientists, partly connected to the Sino-Mongolian joint project on 'Study on the geodynamic process and seismic activity in Ulaanbaatar city and central Asia'. In Asian countries, ASC obtained supports from their governmental agencies. For example, in the ASC Assembly in Ulaanbaatar, D. Terbishdagva, Vice Premier of Mongolia, B. Enkhtuvshin, chairman of the Mongolian Academy of Sciences, and L. Erkhembayar, Consultant to the President of Mongolia, attended the opening ceremony. A new ASC Bureau was elected with Dr. Gary Gibson (Australia) as president and Chen Yun-tai (China) and Bartolome C. Bautista (Philippines) as Vice Presidents. Dr. R.K.Chadha was re-elected as the Secretary General and Dr. S. Demberal was made the Member in the new Bureau. In the closing ceremony, S. Demberel and his team of Local Organizing Committee presented an impressive performance of music and dancing, with the joining of IASPEI and ASC delegates, reflecting the warm atmosphere of ASC with cultural diversity.

The $10^{\text {th }}$ General Assembly was held in Manila, The Philippines, from November 17 to 20, 2014. 232 delegates attended the Assembly from 22 countries, with 89 oral and 44 poster presentations, respectively. Sessions reflected the regional characteristics, like volcano-seismology in addition to the other technical sessions on seismology.

From November 25 to 27, 2016, the 11th Assembly of ASC was held in Melbourne, Australia. The Assembly was jointly organized by
Australian Earthquake Engineering Society (AEES) and highlighted the interdisciplinary exchange of earthquake and engineering seismology. About 90 participants from Australia, China, India, Japan, Indonesia, and New Zealand attended the meeting, with 103 abstracts submitted. Considering the attendance of the delegates, election of the new ASC bureau was postponed to 2017 IAG-IASPEI Joint Assembly in Kobe, Japan. Before that election, Dr. Gary Gibson continued to act as president. In 2017, during the IAG-IASPEI Joint Assembly, ASC held its business meeting and elected its new bureau, with Dr. Paramesh Banerjee (Singapore) as President and Prof. Li Li (China) as Secretary General and Ruben Tatevossian (Russia) and Dr. Toshiaki Yokoi (Japan) as Vice Presidents. The new members added to ASC are D. Srinagesh (India), Esline Galaebiti (Vanuatu) and Gary Gibson (Australia).The ASC secretariat moved back to Beijing, hosted by the Institute of Geophysics of CEA.

The $12^{\text {th }}$ General Assembly was held from May 12 to 14,2018 , in Chengdu, China, in connection to the International Conference for the Decade Memory of the Wenchuan Earthquake and the $4^{\text {th }}$ International Conference on Continental Earthquakes ( $4^{\text {th }}$ ICCE). A Pre-Assembly training course was organized on seismological observation, mainly focusing on central Asian countries where a project on joint seismograph network is going on.

\section{PROMOTING REGIONAL AND LOCAL EARTHQUAKE STUDIES: A GLIMPSE FROM THE PERSPECTIVE OF THE INTERNATIONAL CONFERENCE ON CONTINENTAL EARTHQUAKES (ICCE)}

Promoting the advancement of earthquake studies in Asian-Pacific countries has been one of the major works of the Asian Seismological Commission (ASC) since its establishment taking China as an example. This year China celebrates the century anniversary of modern seismology (Chen et al., 2003). For China, continental earthquakes, a mixture of inter-plate and intra-plate earthquakes, distributed widely and seemingly random in inland regions, have been one of the biggest threats to social sustainability. Study of continental earthquakes has

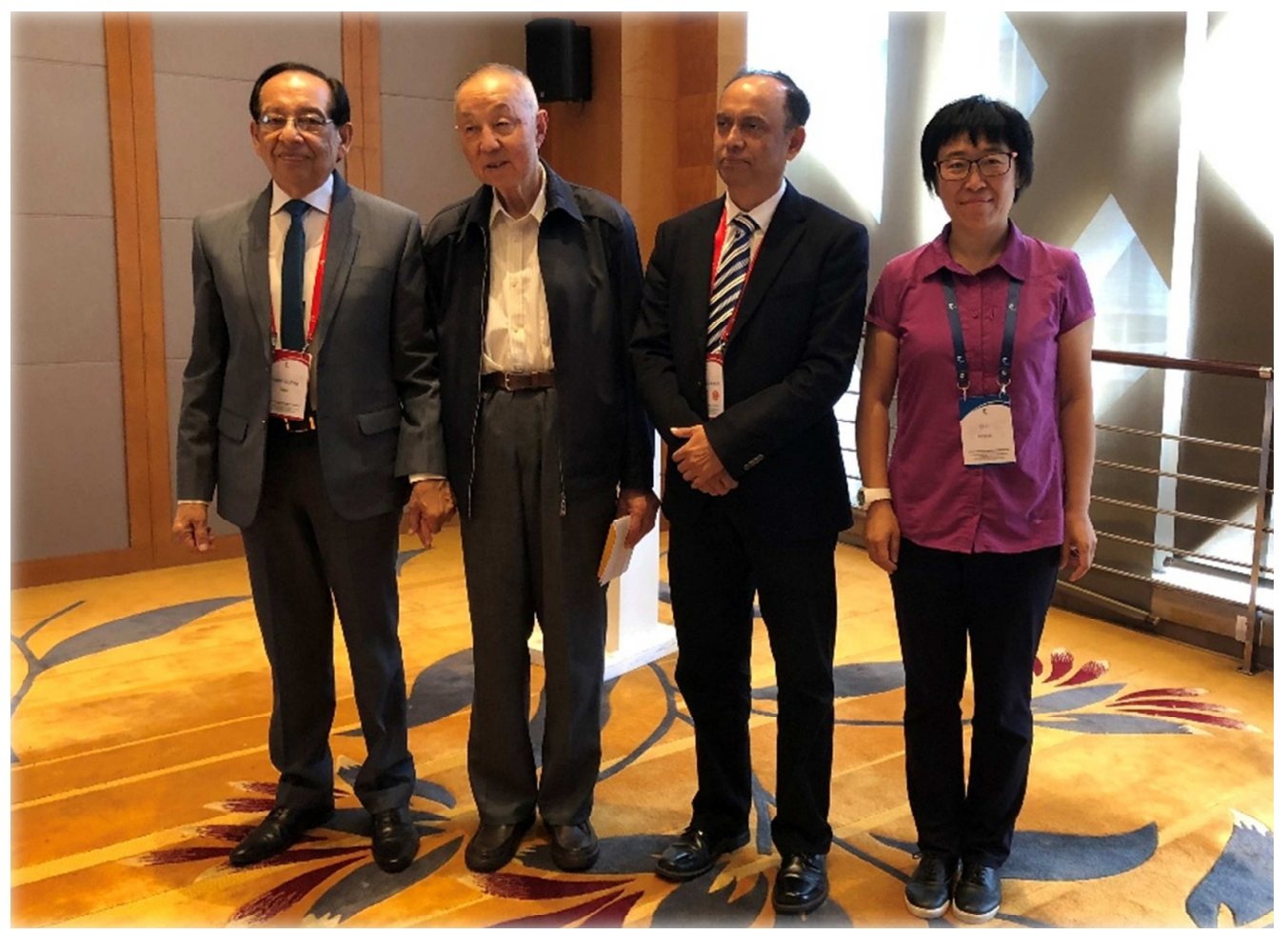

Fig.5. Founding leaders of ASC, together with present leaders. From left to right: Harsh Gupta, Zhu Chuanzhen, Paramesh Banerjee, and Li Li, in 2018 during the 12th Assembly of ASC. 
thus been one of the important issues of earthquake science in China and its surrounding regions encompassing several countries.

The 1st International Symposium on Continental Seismicity and Earthquake Prediction (ISCSEP) was held from September 8 to 14, 1982, in Beijing, organized by the Seismological Society of China (SSC), which was established in 1979. The meeting had 108 experts from 23 countries and was supported by UNESCO and other international organizations. The symposium arranged 5 sessions, namely continental seismicity, continental seismic tectonics, precursors of continental earthquakes, physical basis of earthquake prediction, and disaster risk of continental earthquakes. The Chinese translated proceedings volume was published by Seismological Press (Department of Science, Technology, and Monitoring, State Seismological Bureau, 1984).

The $2^{\text {nd }}$ International Conference on Continental Earthquakes was held in 1992 in Beijing, with its proceedings included in the IASPEI publication series for the IDNDR (Ding and Chen, 1993). The logo of the conference continued to use that of the 1982 conference, with the Zhang Heng seismoscope in the center of the map of the Earth, but with the abbreviation of the meeting on the logo changed from ISCSEP to ICCE. The conference highlighted the modernization of seismology in China and other developing nations. In fact, in the 1990s modernization was the main theme of Chinese seismology (State Seismological Bureau, 1996), with the final result of the starting of the 'digital time' of seismological observation in China as indicated by the multi-level digital seismograph networks (Liu et al., 2003), the starting of the 'space technology time' of seismic geodesy in China as indicated by the GPS-based observational facilities (Wang et al., 2001), and the starting of the 'time of governance by laws' of Chinese seismological science as manifested by the Law of the People's Republic of China on Protecting Against and Mitigating Earthquake Disasters enacted in 1998. The establishment of ASC, in which Chinese seismologists played an important and constructive role, was also a result of such modernization. In the $2^{\text {nd }}$ Assembly of ASC in 1998 in Hyderabad, Chen Yun-tai was the keynote speaker of the opening plenary and Vice chairman of the Federation of Digital Seismograph Networks (FDSN), C. Froidevaux, President of IASPEI and Convener of the plenary session, emphasized his contribution 'to introduce digital seismology into China with a large territory'.

The $3^{\text {rd }}$ International Conference on Continental Earthquakes was held in 2004 in Beijing, with the proceedings volume published by Seismological Press (Secretariat of the Organizing Committee, the Third International Conference on Continental Earthquakes Mechanism, Prediction, Emergency Management \& Insurance, 2007). ASC co-sponsored the conference. The conference used a new logo, which was later friendly misused as the logo of China Earthquake Administration (CEA) in the 5th Assembly of ASC. At that time CEA did not have its logo yet - Its present logo was designed about ten years later. In the conference, one of the important scientific products

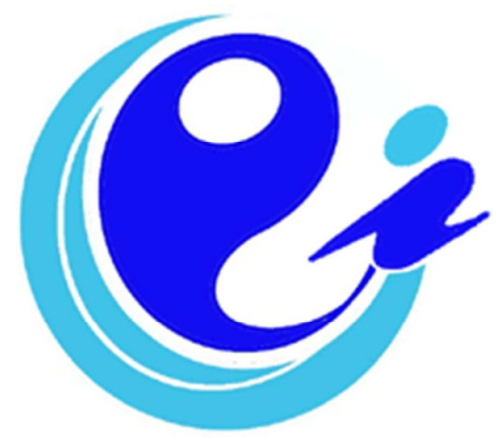

Fig.6. Logo of the 3rd ICCE, designed by Wu Zhongliang

\section{vveIIGIMGit is}

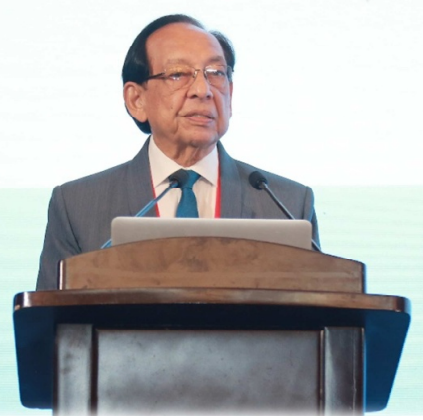

Fig.7. Prof. Harsh Gupta introduced the Wenchuan Revelation in the closing plenary of the $4^{\text {th }}$ ICCE, Chengdu, 2018.

announced was the Tectonic Block Model (Zhang et al., 2003), a systematic inter-disciplinary model of continental earthquakes in China.

From May 12 to 14, 2018, the International Conference for the Decade Memory of the Wenchuan Earthquake, in connection to the 4th International Conference on Continental Earthquakes (4th ICCE) and the 12th Assembly of ASC was held in Chengdu, China. The conference arranged 436 oral and 401 poster presentations. Selected papers were published in Pure and Applied Geophysics as a special issue (Wu et al., 2021). The conference passed the Wenchuan Revelation.

In the conference, it was officially announced that China Seismic Experimental Site (CSES) to be established in the Sichuan-Yunnan region, as a continuation and extension of the west Yunnan earthquake prediction experiment since 1980 and the national experimental site on earthquake monitoring and prediction in Sichuan and Yunnan from 2014 to 2018. Seismic experimental site has been the result of international collaboration (Sun and Wu, 2007). In the 1970s, earthquake prediction experiments were organized in west Xinjiang from 1971 to 1975 and Shanxi from 1971 to 1974, respectively, mainly learning the experiences from the former Soviet Union states. In the 1980s, earthquake prediction experimental sites were constructed in the Beijing-Tianjin-Tangshan-Zhangjiakou area (from 1980 to 1984) and successively in north China (from 1982 to 1986), both supported by UNESCO, and in west Yunnan (since 1980) cooperating with American seismologists. In the ASC Assembly, it was proposed that coordinated distributed experiments (CDEs) be organized for the collaborative and comparative studies of seismic experiments (Wu, 2020), with the hope to 'reactivate' the experimental sites, especially in Asia.

\section{CONCLUDING REMARKS}

This year is the $25^{\text {th }}$ anniversary of Asian Seismological Commission (ASC). The past quarter century witnessed the fast growth of this regional seismological commission and the fruitful capacity building of seismological science in Asia and Pacific. Many people (unfortunately some have passed away till the time of writing this article, such as Prof. S. Yu Balassanian, Prof. C. Froidevaux, Prof. S. Goldin, and Prof. L. Mendes-Victor) made significant contribution to this organization and need special mention.

Up to now ASC has 28 member countries viz., Australia, Armenia, Azerbaijan, Bangladesh, China, Georgia, India, Indonesia, Iran, Israel, Japan, Kazakhstan, Korea, Kyrgyzstan, Malaysia, Mongolia, Myanmar, Nepal, New Zealand, Pakistan, Russia, Tajikistan, Thailand, The Philippines, Turkey, Uzbekistan, Vietnam, and Yemen. Apparently there is still space for expansion and development. At the beginning of 
ASC, it was proposed that there has to be a mechanism to facilitate regional data exchange and joint observation (e.g., Zhu et al., 2002). Till present this goal has not been reached yet. Since its establishment, ASC has experienced the 2004 Sumatra-Andaman earthquake, the 2008 Wenchuan earthquake, the 2011 Tohoku Japan earthquake, as well as other devastating earthquakes in Asian Pacific region. Promoting seismological studies for the seismic safety of the Asian and Pacific people is the radical notion of ASC, and we need to strive for its implementation.

Record of the history of ASC is till 2018 in this review. It is well known that since 2019 the world has been disturbed by COVID-19 and almost everything is being reshaped and in debate. ASC spent a significant effort in overcoming the difficulties, in which the stories deserves another separate article. Nevertheless ASC is on its track. Aiming at the vision of ASC, there is still a long way to go, which needs the joint effort of seismologists of different countries and of different generations as well.

\section{Acknowledgements and Additional Remarks}

Among the authors of this article, Zhu was the secretary general (1996-2004) and president (2004-2008) of ASC, Wu was the executive member (1999-2003, 2011-2015), vice president (20032007), and president (2007-2011) of IASPEI, and Li was the executive member (2015-2019) and vice president (2019-2023) of IASPEI and secretary general (2019-) of ASC, representing the old generation, the mid generation, and the young generation, respectively, of Chinese seismologists witnessing, joining in, and contributing to the growth of ASC. In the article we used the convention of Chinese names to put family names first. As a matter of fact, one of the interesting cultural diversities associated with ASC is the names of people in different countries. Communication with this diverse cultural background is sometimes a challenge, and in most cases a fun, of the community. We enjoyed this very much and thank the understanding and friendship of our friends from different countries/ regions.

On the international side, we sincerely thank the supports and helps from the International Union of Geodesy and Geophysics (IUGG), International Association of Seismology and Physics of the Earth's Interior (IASPEI), and European Seismological Commission (ESC). On the China side, we thank China Association of Science and Technology (CAST), China Earthquake Administration (CEA), Ministry of Science and Technology of China (MOST), National natural Science Foundation of China (NSFC), and the Seismological Society of China (SSC), for various supports and helps; We especially thank the Institute of Geophysics of CEA, for assistance in hosting the ASC secretariat. Ms. Su Xiaolan contributed much to the work of ASC, including the collection of data for writing this article.

\section{References}

Chen, Y.-T., Wu, Z. L. and Xie, L.L. (2003) Centennial national and institutional reports: seismology and physics of the Earth's interior - China (Beijing). In: W. H. K. Lee, H. Kanamori, P. C. Jennings and C. Kisslinger (Eds.) International Handbook of Earthquake and Engineering Seismology, Part B. Amsterdam: Academic Press, pp.1317-1321.

Department of Science, Technology, and Monitoring, State Seismological Bureau (Eds.), (1984) Collected Papers of the International Symposium on Continental Seismicity and Earthquake Prediction. Beijing: Seismological Press (in Chinese).

Ding, G.Y. and Chen, Z. L. (Eds.), (1993) Continental Earthquakes - Selected Papers of the Second International Conference on Continental Earthquakes. IASPEI Publication Series for the IDNDR, Volume No.3. Beijing: Seismological Press.

Dixit, A.M. (Ed.), (2004) Proceedings of the Symposium on Seismology, Earthquake Hazard Assessment and Risk Management in conjunction with the Fourth General Assembly of the Asian Seismological Commission, 24-26 November 2002, Kathmandu. Kathmandu: National Society for Earthquake Technology - Nepal (NSET) Publication Series 17.

Liu, R.F., Wu, Z.L., Yin, C.M., Chen, Y.-T. and Zhuang, C.T. (2003) Development of China Digital Seismological Observational Systems. Acta Seismologica Sinica (English edition), v.16, pp.568-573.

Secretariat of the Organizing Committee, the Third International Conference on Continental Earthquakes - Mechanism, Prediction, Emergency Management \& Insurance (Eds.), (2007) Collected Papers of the Third International Conference on Continental Earthquakes. Beijing: Seismological Press.

State Seismological Bureau (Eds.), (1996) Achievements of Seismic Hazard Prevention and Reduction in China - Dedicated to the $30^{\text {th }}$ International Geological Congress. Beijing: Seismological Press.

Su, X.L., Zhu, C.Z., Wu, Z.L. and Huang, J. (2000) How much knowledge has been obtained from an earthquake? A survey of seismological publications. Earthquake Research in China (English edition), v.14, pp.379-389.

Sun, Q.Z. and Wu, S.G. (2007) Development of the Earthquake Monitoring and Prediction in China during 1966-2006. Beijing: Seismological Press (in Chinese), pp.490-509.

Wang, Q., Zhang, P.Z., Freymueller, J.T., Bilham, R., Larson, K.M., Lai, X.A., You, X.Z., Niu, Z.J., Wu, J.C., Li, Y.X., Liu, J.N., Yang, Z.Q. and Chen, Q.Z. (2001) Present day crustal deformation in China constrained by Global Positioning System measurements. Science, v.294, pp.574-577.

Wu, Z.L. (2020) Seismic experimental sites: challenges and opportunities. Jour. Geol. Soc. India, v.95, pp.113-116, doi: 10.1007/s12594-020-1400-9.

Wu, Z.L., Zhang, Y.X., Goebel, T.H.W., Huang, Q.H., Williams, C.A., Xing, H.L. and Rundle, J.B. (Eds.), (2021) Continental Earthquakes: Physics, Simulation, and Data Science. Basel: Birkhäuser Verlag GmbH.

Zhang, P.Z., Deng, Q.D., Zhang, G.M., Ma, J., Gan, W.J., Min, W., Mao, F.Y. and Wang, Q. (2003) Active tectonic blocks and strong earthquakes in the continent of China. Science in China Series D: Earth Sciences, v.46(S2), pp.13-24.

Zhu, C.Z., Chen, Y.-T., Liu, R.F., Xu, L.S. and Wu, Z.L. (2002) Towards a virtual Asian-Pacific seismological network. Earthquake Research in China (English edition), v.16, pp.298-303. 